\title{
A midwife led debriefing session after operative childbirth did not reduce postpartum depression
}

Small $R$, Lumley J, Donohue L, et al. Randomised controlled trial of midwife led debriefing to reduce maternal depression after operative childbirth. BMJ 2000 Oct 28;321:1043-7.

\section{QUESTION: In women who give birth by caesarean section, forceps, or vacuum extraction, is a debriefing session led by a midwife better than standard care for reducing maternal depression at 6 months postpartum?}

Design

Randomised (allocation concealed*), unblinded,* controlled trial with 6 months of follow up.

Setting

A large maternity teaching hospital in Melbourne, Victoria, Australia.

\section{Patients}

1041 women who had operative deliveries. Exclusion criteria were women with stillbirths or babies weighing $<1500 \mathrm{~g}$, insufficient fluency in English, or ill mothers or ill babies. Follow up was $88 \%$ (62\% were 25 to 34 y of age, $27 \%$ were $\geqslant 35$ y of age).

\section{Intervention}

Women were allocated to debriefing $(n=520)$ or standard care $(n=521)$. Debriefing occurred before women were discharged from the hospital. 1 of 2 research midwives met with each woman for up to 1 hour to talk about the woman's labour, birth, and postdelivery events and experiences. The content of the discussion was determined by the woman's experiences and concerns.

Australian

Commonwealth

Department of Health,

Housing, and

Community Services.

For correspondence:

Ms $R$ Small, Centre for

the Study of Mothers'

and Children's Health,

School of Public

Health, La Trobe

University, Carlton

Victoria 3053

Australia. Fax +613

83418555

A midwife led debriefing session v standard care after operative childbirth $\dagger$

\begin{tabular}{|c|c|c|c|c|}
\hline Outcomes at 6 months & Debriefing & $\begin{array}{l}\text { Standard } \\
\text { care }\end{array}$ & RRI $(95 \%$ Cl) & NNH \\
\hline Depression ( $\geqslant 13$ on EPDS) & $17 \%$ & $14 \%$ & $20 \%(-11$ to 62$)$ & Not significant \\
\hline & & & \multicolumn{2}{|c|}{ Mean difference $(\mathrm{Cl})$} \\
\hline $\begin{array}{l}\text { SF-36 subscale role functioning } \\
\text { (emotional) mean scores }\end{array}$ & 73.3 & 79.0 & \multicolumn{2}{|l|}{$5.66(0.87$ to 10.5$)$} \\
\hline
\end{tabular}

\section{Main outcome measures}

Maternal depression (score $\geqslant 13$ on the Edinburgh Postnatal Depression Scale) and overall maternal health status (SF-36) at 6 months. These scales were assessed by a postal questionnaire. A secondary outcome was satisfaction with care.

\section{Main results}

Debriefing and standard care did not differ significantly in rates of postpartum depression at 6 months (table). Debriefing led to poorer health status on 7 of 8 SF-36

EPDS = Edinburgh Postnatal Depression Scale. Other abbreviations defined in glossary; RRI, NNH, mean difference, and $\mathrm{Cl}$ calculated from data in article. scales, but the difference was only statistically significant for role functioning (emotional) (table). Groups did not differ for satisfaction with care. The study had $>80 \%$ power to detect a 33\% difference for depression and a $10 \%$ difference in satisfaction with care.

\section{Conclusion}

In women who gave birth by caesarean section, forceps, or vacuum extraction, midwife led debriefing did not reduce depression and led to poorer emotional role functioning.

*See glossary.

\section{COMMENTARY}

The study by Small et al clearly shows that a brief counselling session is not effective for alleviating the distress engendered by an operative delivery. The study methods were impeccable, the population was clearly in need, the intervention was expertly done, and the outcomes studied were substantive. In addition, similar interventions in various post-traumatic situations have also been shown to be ineffective or counterproductive. ${ }^{1}$ It is tempting to throw up one's hands and conclude that nothing can be done, but these women need help and appreciate the process; $94 \%$ of the women found the debriefing session helpful. Perhaps the intervention was both too little and too late. Support during labour results in a substantial reduction in the need for operative delivery and has a direct preventive effect on postpartum depression. ${ }^{2}$

Regardless of its cause, depression may be alleviated by enhanced postpartum professional or social support, or both. ${ }^{3}$ The underlying message of the study by Small $e t a l$ is not to withdraw support but to provide the needed support more effectively, earlier, and for a longer period.

Murray Enkin, MD McMaster University Hamilton, Ontario, Canada

1 Wessely S, Bisson J. Brief psychological interventions ("debriefing") for trauma-related symptoms and prevention of post traumatic stress disorder. Cochrane Database Syst Rev 2001:(1):CD00560.

2 Hodnett ED. Caregiver support for women during childbirth. Cochrane Database Syst Rev 2001;(1):CD000199.

3 Ray KL, Hodnett ED. Caregiver support for postpartum depression. Cochrane Database Syst Rev 2001;(1):CD000946. 